\title{
Application of Box-Behnken Design in Optimization of Glucose Production from Oil Palm Empty Fruit Bunch Cellulose
}

\author{
Satriani Aga Pasma, Rusli Daik, Mohamad Yusof Maskat, and Osman Hassan \\ School of Chemical Sciences and Food Technology, Faculty of Science and Technology, Universiti Kebangsaan Malaysia, \\ 43600 Bangi, Selangor, Malaysia \\ Correspondence should be addressed to Rusli Daik; rusli@ukm.my
}

Received 23 July 2013; Accepted 8 October 2013

Academic Editor: Yulin Deng

Copyright (C) 2013 Satriani Aga Pasma et al. This is an open access article distributed under the Creative Commons Attribution License, which permits unrestricted use, distribution, and reproduction in any medium, provided the original work is properly cited.

\begin{abstract}
Oil palm empty fruit bunch fiber (OPEFB) is a lignocellulosic waste from palm oil mills. It contains mainly cellulose from which glucose can be derived to serve as raw materials for valuable chemicals such as succinic acid. A three-level Box-Behnken design combined with the canonical and ridge analysis was employed to optimize the process parameters for glucose production from OPEFB cellulose using enzymatic hydrolysis. Organosolv pretreatment was used to extract cellulose from OPEFB using ethanol and water as the solvents. The extracted cellulose was characterized by thermogravimetric analysis, FTIR spectroscopy, and field emission scanning electron microscopy. Hydrolysis parameters including amount of enzyme, amount of cellulose, and reaction time were investigated. The experimental results were fitted with a second-order polynomial equation by a multiple regression analysis and found that more than $97 \%$ of the variations could be predicted by the models. Using the ridge analysis, the optimal conditions reaction time found for the production of glucose was 76 hours and $30 \mathrm{~min}$, whereas the optimum amount of enzyme and cellulose was $0.5 \mathrm{~mL}$ and $0.9 \mathrm{~g}$, respectively. Under these optimal conditions, the corresponding response value predicted for glucose concentration was $169.34 \mathrm{~g} / \mathrm{L}$, which was confirmed by validation experiments.
\end{abstract}

\section{Introduction}

Bioconversion of lignocellulosic waste materials to chemicals and fuels are receiving interest as they are low cost, renewable, and widespread in nature [1]. Malaysia is well acknowledged for its potential in renewable resources of lignocellulosic materials such as oil palm waste, sugar cane bagasse, and rice straw. At present Malaysia is the largest exporter and producer of palm oil and its production accounts approximately $40-60 \%$ of world total palm oil over the 25 years $[2,3]$. In the process of extraction of palm oil from oil palm fruit, a lignocellulosic material, namely, OPEFB, is generated as a main solid residue, with every ton of fresh fruit bunches producing $\sim 0.22$ ton of OPEFB [4]. In Malaysia, $~ 17$ million tons of OPEFB is produced every year. Commonly, this biomass is burnt in incinerators, and it does not only create environmental pollution problems but it also offers limited value to the industry. Several approaches have been developed to utilize OPEFB fibres to produce valuable materials including paper pulp, composite boards, thermoset polymer, and activated carbon [5]

OPEFB consists of $67 \%$ of holocellulose (cellulose and hemicellulose) and $24 \%$ of lignin [6]. Cellulose ( $\beta$-glucan) is a polymer of glucose [7] and can be used as a substrate for the production of a wide variety of compounds by chemical and biochemical processes. One such compound is succinic acid, which is extensively used in food, pharmaceuticals, and manufacturing of biodegradable polymers [8]. Production of glucose from OPEFB cellulose increased the yield and concentration of glucose produced compared to using acid or base pretreated OPEFB as reported before. Enzymatic hydrolysis using cellulase from Trichoderma reesei (a mixture of endoglucanases, exoglucanases, and $\beta$-glucosidase) is widely used for the degradation of cellulose into soluble oligo glucan/oligomers, cellobiose, and glucose [9]. In this project, a mixture of two enzymes was used to carry out the reaction. Novozyme Celluclast $1.5 \mathrm{~L}$ is a brand for cellulase enzyme that is capable to break the cellulose chains, particularly at middle 
and chain end sections into cellobiose (the dimer of glucose). Whereas, Novozyme 188 that mainly contains $\beta$-glucosidase was used to optimize the glucose production since it breaks the cellobiose chains into glucose.

Optimization of parameters in reaction is one of the most important stages in the development of an efficient and economic production of high value products from renewable sources. The traditional "one-factor-at-a-time approach" is time consuming, and moreover the interactions between independent variables are not considered. Response surface methodology (RSM) is an effective optimization tool wherein many factors and their interactions can be identified with fewer experimental trials [10].

RSM has been widely used in various fields including food process operations, new product development, biotechnology-media composition, and bioprocessing such as enzymatic hydrolysis and fermentation [10]. The RSM is a collection of mathematical and statistical techniques for designing experiments, building models, evaluating the effects of factors, and searching optimum condition of factors for desired responses. The optimization process of this methodology involves studying the response of statistically designed combinations, estimating the coefficients by fitting it in mathematical model that fits best the experimental conditions, predicting the response of the fitted model, and checking the adequacy of the model. Central composite design (CCD) and Box-Behnken design (BBD) are amongst the most commonly used in various experiments [11]. Box-Behnken design allows calculation of the response to be made at intermediate levels which were not experimentally studied. A three-level Box-Behnken design was employed in the present study and the optimal conditions were determined through a minimal experiment number compared with other designs [12].

The objective of this study is to optimize the glucose production from OPEFB cellulose via enzymatic hydrolysis with the help of Box-Behnken design, followed by canonical and ridge analyses. OPEFB was treated by organosolv method for lignin and hemicellulose removal. In this context, reaction time, amount of enzyme, and amount of substrates were optimized. Enzymatic hydrolysis was also carried out on commercially available cellulose for comparison purpose.

\section{Materials and Methods}

2.1. Raw Material. OPEFB fibers were collected from local palm oil mill (United Oil Palm Industries SdnBhd, Malaysia), sun dried, and ground to particles with diameter of $<1 \mathrm{~mm}$. The OPEFB biomass was then oven dried at $105^{\circ} \mathrm{C}$ overnight and was analyzed following the standard method for determination of its main composition [13].

2.2. Chemicals and Enzymes. Two types of standard cellulose from Sigma-Aldrich were used in this study, namely, fiber cellulose and microcrystalline cellulose. Solvent and other chemicals were obtained from R\&M Chemicals. Celluclast $1.5 \mathrm{~L}$ (cellulase) and Novozyme 188 (cellobiase) were obtained from Novozymes Malaysia SdnBhd.
2.3. Autonydrolysis Pretreatment. Autohydrolysis pre-treatment was conducted for the delignification process of OPEFB. OPEFB fibers (30 grams) were loaded into $4 \mathrm{~L}$ stainless steel reactor $\left(98 \mathrm{kPa}, 120^{\circ} \mathrm{C}\right)$ and were supplemented with appropriate amount of deionized water. The autohydrolysis was carried out at $120^{\circ} \mathrm{C}$ for $1-2$ hours.

2.4. Organosolv Treatment. Autohydrolyzed OPEFB (10 grams) was milled and mixed with $80 \%$ aqueous ethanol $\left(\mathrm{EtOH} / \mathrm{H}_{2} \mathrm{O}: 8 / 2 \mathrm{v} / \mathrm{v}\right.$ ) and $0.2 \% \mathrm{w} / \mathrm{w}$ sulphuric acid as catalyst [14]. The mixture was heated at $120^{\circ} \mathrm{C}$ for 1 hour and filtered and washed with methanol [14]. This was followed by treatment with hydrogen peroxide $\left(\mathrm{H}_{2} \mathrm{O}_{2}\right) 2 \%$ for 4 hours at $50^{\circ} \mathrm{C}$ to obtain cellulose.

2.5. Enzymatic Hydrolysis. Enzymatic hydrolysis experiment was carried out in a $100 \mathrm{~mL}$ shaking flask at $40^{\circ} \mathrm{C}$ and $145 \mathrm{rpm}$ inside an incubator shaker. The cellulase-catalysed hydrolysis of different cellulose substrates (untreated or pretreated) was carried out in a stirred flask. In a typical hydrolysis reaction, $500 \mathrm{mg}$ of cellulose was added to $9 \mathrm{~mL}$ acetate buffer $(50 \mathrm{~mm}$, $\mathrm{pH} 4)$ and incubated for 2 hours $\left(40^{\circ} \mathrm{C} ; 145 \mathrm{rpm}\right)$. After this preincubation step, hydrolysis was initiated by adding $0.1 \mathrm{~mL}$ of $10 \mathrm{mg} / \mathrm{mL}$ cellulase (activity: $700 \mathrm{EGU} / \mathrm{g}$ ). The reaction medium was withdrawn repeatedly at a specific time interval to determine the progress of the reaction which was stopped by incubating the withdrawn sample at $90^{\circ} \mathrm{C}$ for $20 \mathrm{~min}$ [15]. Then, the sample was diluted in ultrapure water and filtered $(0.2 \mu \mathrm{m})$ prior to analysis by high performance liquid chromatography (HPLC).

The same procedure was also performed for the cellulose extracted from OPEFB. The reaction was carried out at $40^{\circ} \mathrm{C}$, for 48-94 hours. The amount of cellulose and enzyme used was varied from $300 \mathrm{mg}$ to $500 \mathrm{mg}$ and from $0.3 \mathrm{~mL}$ to $0.7 \mathrm{~mL}$, respectively.

2.6. Box-Behnken Design. Based on the preliminary onefactor-at-a-time experiments, variables such as duration of reaction, amount of samples, and total enzymes were identified to have strong effects on the response. Therefore, these factors were selected as the variables tested in the 15-run experiment of the Box-Behnken design experiment.

Table 1 shows the Box-Behnken design matrix of the experiment of 15 trials. As shown in Table 1, the three factors chosen for this study were designated as $X_{1}, X_{2}$, and $X_{3}$ and prescribed into three levels, coded $+1,0,-1$ for high, intermediate, and low value, respectively. Three test variables were coded according to the following equation:

$$
x_{i}=\frac{X_{i}-X_{o}}{\Delta X} \quad i=1,2,3,
$$

where $x_{i}$ is the coded value of an independent variable; $X_{i}$ is the actual value of an independent variable; $X_{o}$ is the actual value of an independent variable at centre point; and $\Delta X$ is the step change value of an independent variable. All experiments were carried out in triplicate, and the averages of glucose concentration were taken as response [12]. 
TABLE 1: Levels and code of variables chosen for Box-Behnken design.

\begin{tabular}{lccccc}
\hline \multirow{2}{*}{ Variables } & \multicolumn{3}{c}{ Symbol } & \multicolumn{3}{c}{ Coded levels } \\
& Uncoded & Coded & -1 & 0 & +1 \\
\hline Hydrolysis reaction time (h) & $X_{1}$ & $x_{1}$ & 48 & 76 & 94 \\
Amount of enzymes $(\mathrm{mL})$ & $X_{2}$ & $x_{2}$ & 0.1 & 0.2 & 0.3 \\
Amount of samples $(\mathrm{g})$ & $X_{3}$ & $x_{3}$ & 0.3 & 0.5 & 0.7 \\
\hline
\end{tabular}

For predicting the optimal point, a second-order polynomial model was fitted to correlate the relationship between independent variables and response (glucose concentration). The equation for three factors is stated as follows:

$$
\begin{aligned}
Y= & \beta_{0}+\beta_{1} x_{1}+\beta_{2} x_{2}+\beta_{3} x_{3}+\beta_{12} x_{1} x_{2} \\
& +\beta_{13} x_{1} x_{3}+\beta_{23} x_{2} x_{3}+\beta_{11} x_{1}^{2}+\beta_{22} x_{2}^{2}+\beta_{33} x_{3}^{2},
\end{aligned}
$$

where $Y$ is the predicted response; $\beta_{0}$ is model constant; $x_{1}, x_{2}$, and $x_{3}$ are independent variables; $\beta_{1}, \beta_{2}$, and $\beta_{3}$ are linear coefficients; $\beta_{12}, \beta_{13}$ and $\beta_{23}$ are cross-product coefficients; and $\beta_{11}, \beta_{22}$, and $\beta_{33}$ are the quadratic coefficients. The quality of fit of the polynomial model equation was expressed by the coefficient of determination $R^{2}$.

2.7. Statistical Data Analysis. The analyses of regression and variance were carried out using the RSREG procedure of the Statistical Analysis System (SAS) (Version 9.03, SAS Institute Inc., Cary, NC, USA). Both canonical and ridge analyses were also carried out.

2.8. Characterization. Fourier transform infrared spectra of raw and treated OPEFB fibers were recorded using Perkin Elmer Fourier Transform Infrared (FTIR) model GX. The powdered samples for each type were mixed with $\mathrm{KBr}$ and compressed into pellets. Samples were scanned from 400 to $4000 \mathrm{~cm}^{-1}$. Thermogravimetric analysis (TGA) was carried out using a Mettler Toledo model TGA/SDTA $851^{\mathrm{e}}$. Samples of approximately $6 \mathrm{mg}$ were placed in alumina pans and heated from 30 to $800^{\circ} \mathrm{C}$ at $10^{\circ} \mathrm{C} \mathrm{m^{-1 }}$, under a dynamic flow of nitrogen $\left(50 \mathrm{~mL} \mathrm{~min}^{-1}\right)$. Morphology of the samples was examined by using Zeiss Field Emission Scanning Electron Microscope (FESEM) model Supra 46VP. FESEM images were recorded using an accelerating voltage of $3-5 \mathrm{kV}$.

The glucose concentration was determined by using High Performance Liquid Chromatography (HPLC) and glucose meter. The system used for HPLC was Waters HPLC system, and evaporative light scattering detectors (ELSD) was used as detectors. Glucose was determined using a Zorbax $\mathrm{NH}_{2}$ column and acetonitrile: water $80: 20$ as the mobile phase at a flow rate of $1 \mathrm{~mL} / \mathrm{min}$. The retention time of glucose is $13.32 \mathrm{~min}$ ( $\mathrm{rsd} \pm 0.56 \%$ ). Quantification was based on calibration curves established using standard glucose purchased from Sigma-Aldrich.

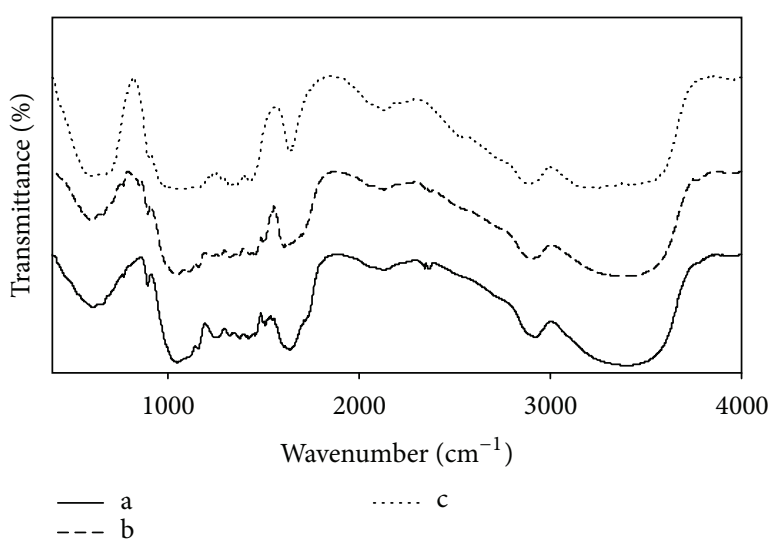

FIgURE 1: FTIR spectra for (a) raw OPEFB, (b) delignified OPEFB, and (c) OPEFB cellulose.

\section{Results and Discussion}

\subsection{Characterization of OPEFB Cellulose}

3.1.1. FTIR Spectroscopy. Figure 1 shows the FTIR spectra of cellulose extracted from OPEFB (OPEFB cellulose), raw OPEFB, and delignified OPEFB. The peaks ascribed to lignin appeared at 1501 and $1512 \mathrm{~cm}^{-1}$ that are due to $\mathrm{C}=\mathrm{C}$ stretching and $\mathrm{C}=\mathrm{C}$ aromatic skeletal vibration of lignin, respectively. However, the two peaks of lignin were not observed in the FTIR spectra of the delignified OPEFB (Figure 1,b) and OPEFB cellulose (Figure 1,c). The peak attributed to hemicellulose was observed in the spectra of the raw OPEFB and delignified OPEFB (Figure 1,b) at $1732-1735 \mathrm{~cm}^{-1}$ due to $\mathrm{C}=\mathrm{O}$ stretching. However, the corresponding peaks were disappeared in the spectrum of OPEFB cellulose (Figure 1,c). This observation indicated that the organosolv treatment was able to remove the lignin as well as hemicellulose from OPEFB fibers. The peak observed at $898 \mathrm{~cm}^{-1}$ is attributed to the presence of $\beta$-glucoside linkage between glucose units in cellulose [16]. All FTIR spectra in this study showed a $\beta$ glucoside linkage peak including the FTIR spectrum for the obtained OPEFB cellulose (Figure 1,c).

3.1.2. Thermal Analysis of OPEFB Cellulose. Figure 2 presents the TGA thermograms and the corresponding DTG curves of the raw OPEFB, delignified OPEFB, and OPEFB cellulose. A clear "shoulder" at around $250-300^{\circ} \mathrm{C}$ is normally assigned to the thermal decomposition of hemicellulose [17]. The high temperature "tails" around $400-600^{\circ} \mathrm{C}$ were normally ascribed to degradation of lignin. For the raw OPEFB (Figure 2(c)), hemicelluloses shoulder peaks were not obvious because it is overlapped with main peaks of cellulose. In the thermogram for delignified OPEFB (Figure 2(b)), the first peak appears at around $300^{\circ} \mathrm{C}$ (shoulder) resembling the thermal decomposition of hemicellulose. There is no tail appears within the range of $400-600^{\circ} \mathrm{C}$ indicating that the delignification process was successful. In the case of cellulose obtained from organosolv and $\mathrm{H}_{2} \mathrm{O}_{2}$ treatments, there is no shoulder and tails present in the thermogram indicating that 


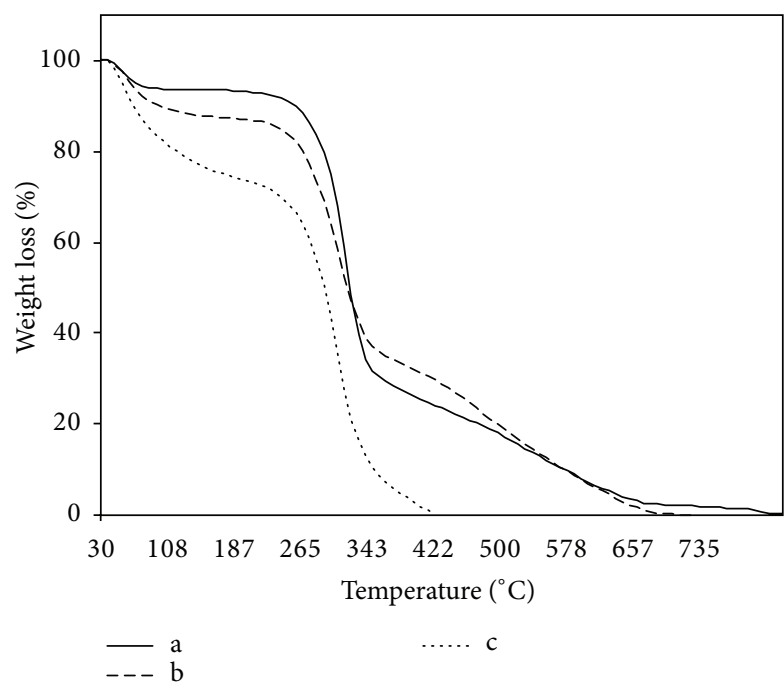

(A)

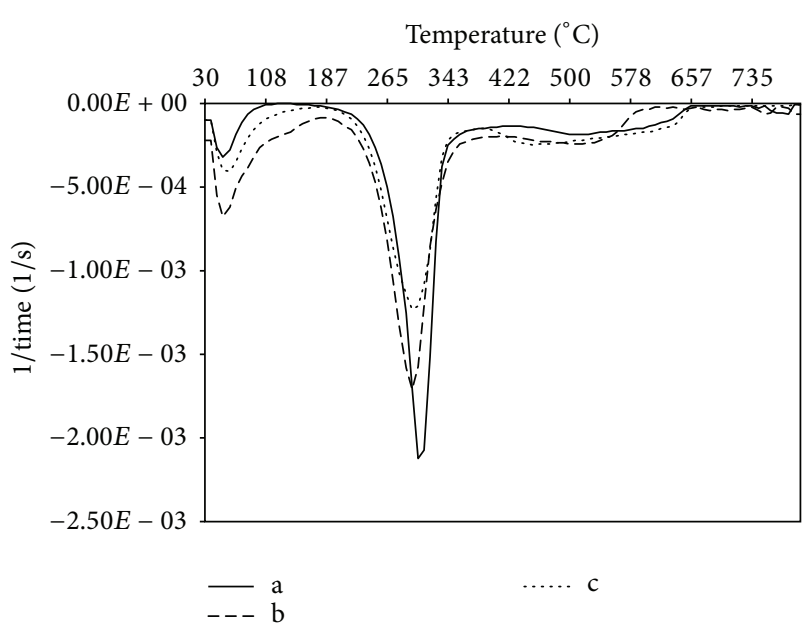

(B)

FIgURE 2: TGA thermograms and DTG curves of (a) OPEFB cellulose, (b) delignified OPEFB, and (c) raw OPEFB.

lignin and hemicellulose were successfully removed. Thermal decomposition at around $310^{\circ} \mathrm{C}$ showed that OPEFB cellulose was successfully obtained (Figure 2(a)).

3.1.3. Morphology of OPEFB Fibers. SEM micrographs of raw OPEFB, delignified OPEFB, and obtained cellulose (OPEFB cellulose) are shown in Figure 3. A rigid appearance can be seen for raw OPEFB material (Figure 3(a)). The figure shows that raw OPEFB fibers exhibit stiff and hard surfaces. Delignification of OPEFB reduced the stiff appearance and some parts of the fibers were split and became more refined. The images also showed that some fibers were broken. Figure 3(c) shows the SEM image of obtained cellulose (OPEFB cellulose) after delignification and organosolv treatment. The appearance is quite different and the length and diameter of fibers were reduced. This is probably due to the decrease in spiral angle around the fibre axis and increase in molecular orientation after pretreatment. A fair amount of randomness
TABLE 2: Effect of different parameters on enzymatic hydrolysis of OPEFB cellulose.

\begin{tabular}{lcccc}
\hline Run & $\begin{array}{c}\text { Amount of } \\
\text { substrate }(\mathrm{g})\end{array}$ & $\begin{array}{c}\text { Total enzymes } \\
(\mathrm{mL})\end{array}$ & $\begin{array}{c}\text { Reaction time } \\
(\text { Hours })\end{array}$ & $\begin{array}{c}\text { Glucose } \\
\text { concentration } \\
(\mathrm{g} / \mathrm{L})\end{array}$ \\
\hline 1 & 0.7 & 0.2 & 48 & 91.8 \\
2 & 0.5 & 0.1 & 94 & 97.2 \\
3 & 0.5 & 0.3 & 48 & 97.2 \\
4 & 0.5 & 0.3 & 94 & 93.6 \\
5 & 0.3 & 0.2 & 48 & 55.8 \\
6 & 0.3 & 0.2 & 94 & 39.6 \\
7 & 0.7 & 0.2 & 48 & 122.4 \\
8 & 0.7 & 0.2 & 94 & 167.4 \\
9 & 0.3 & 0.1 & 76 & 21.6 \\
10 & 0.7 & 0.3 & 76 & 97.2 \\
11 & 0.7 & 0.1 & 76 & 48.6 \\
12 & 0.7 & 0.3 & 76 & 100.8 \\
13 & 0.5 & 0.2 & 76 & 52.2 \\
14 & 0.5 & 0.2 & 76 & 54.0 \\
15 & 0.5 & 0.2 & 76 & 55.8 \\
\hline
\end{tabular}

is introduced to the orientation of the crystallites due to removal of noncellulosic matters [15] leading to the formation of fibers with smaller diameter and length.

3.2. Effect of Pretreatments on Enzymatic Hydrolysis of Cellulose. Effect of pretreatments on enzymatic hydrolysis of various cellulose substrates is shown in Figure 4. Plots in Figure 4 show that glucose concentration increased with reaction time. Figure 4 also indicated that organosolv treated OPEFB cellulose produced the highest glucose concentration followed by acetic acid treated OPEFB, microcrystalline cellulose, cellulose fiber, and delignified OPEFB. The concentration of glucose produced from the organosolv treated OPEFB cellulose was $36.5 \mathrm{~g} / \mathrm{L}$ with 48 hours reaction time and used minimum amount of enzyme. The sugar recovery for organosolv treated OPEFB cellulose is $0.73 \mathrm{~g} / \mathrm{g}$.

Table 2 shows the effect of different parameters on enzymatic hydrolysis of cellulose extracted from OPEFB. It was observed that model run number 8 produced the highest amount of glucose, that is, $167.4 \mathrm{~g} / \mathrm{L}$. The lowest glucose concentration was produced by run number 9 with concentration of only $21.6 \mathrm{~g} / \mathrm{L}$. The glucose concentration increased with the increasing amount of substrate. The longer reaction time also increased the glucose concentration. The best total enzyme to produce high glucose concentration is $0.2 \mathrm{~mL}$. This means that the use of the same amount of novozyme 188 and celluclast $(0.1 \mathrm{~mL}: 0.1 \mathrm{~mL})$ can improve the activity of the two enzymes as catalyst.

\subsection{Statistical Analysis}

3.3.1. Model Building and Statistical Significance Test. A 15run Box-Behnken design with three factors and three levels, including three replicates at the centre point, was used for 


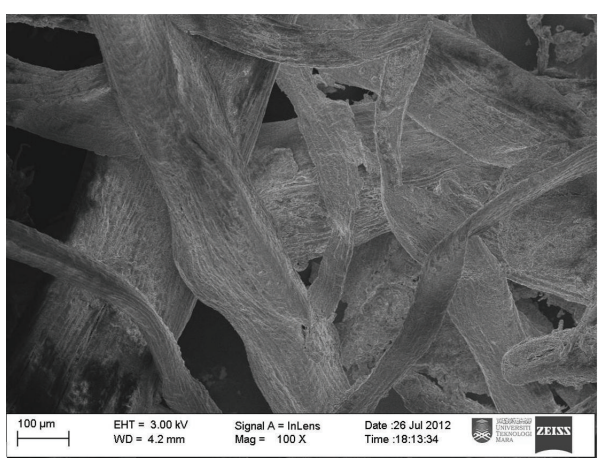

(a)

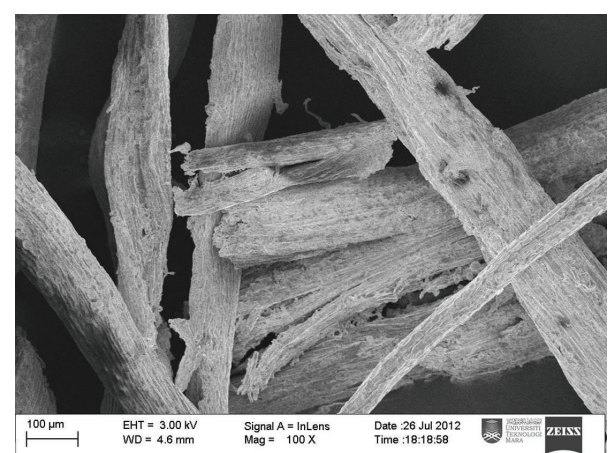

(b)

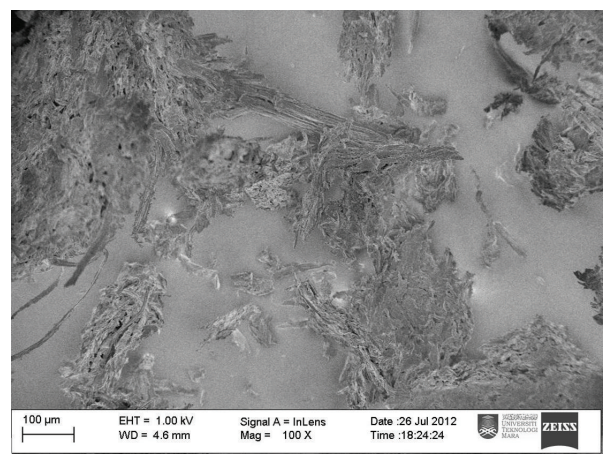

(c)

Figure 3: SEM images of (a) raw OPEFB fibers (b) delignified OPEFB (c) OPEFB cellulose.

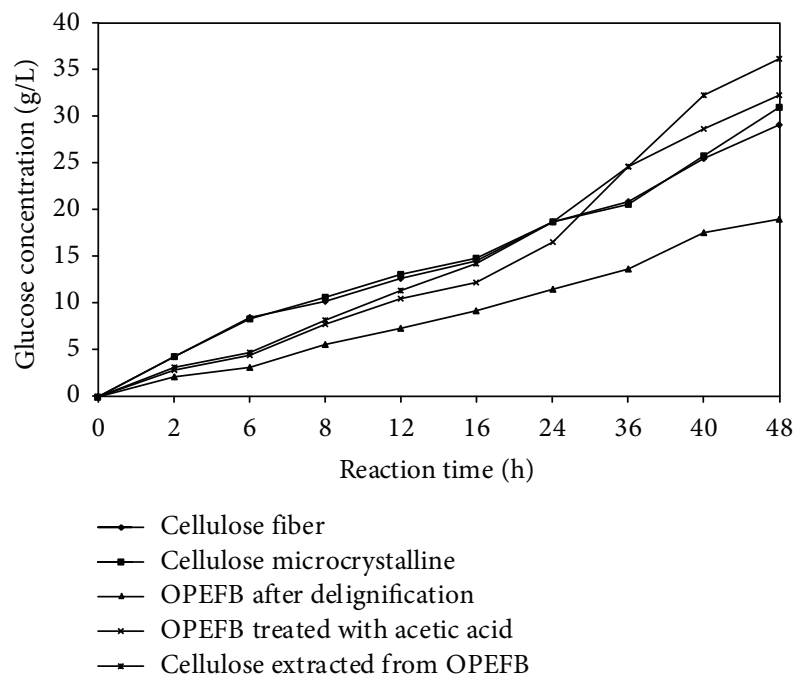

Figure 4: Effect of pre-treatments on enzymatic hydrolysis of various cellulose substrates.

appropriate second-order responses surface. The three centre point runs were added to provide as a measure of process stability and inherent variability. The considerable variation in the glucose concentration produced from OPEFB cellulose under different conditions is shown in Table 3. The glucose concentration predicted by the final quadratic model along with corresponding values observed was given too. The
TABLE 3: Box-Behnken design with experimental and predicted values of glucose concentration.

\begin{tabular}{ccccccc}
\hline \multirow{2}{*}{ Run } & $x_{1}$ & $x_{2}$ & $x_{3}$ & \multicolumn{3}{c}{ Glucose concentration $(\mathrm{g} / \mathrm{L})$} \\
\hline 1 & -1 & -1 & 0 & 94.95 & 91.8 & -3.15 \\
2 & -1 & -1 & 0 & 94.95 & 97.2 & 2.25 \\
3 & 1 & 1 & 0 & 94.95 & 97.2 & 2.25 \\
4 & 1 & 1 & 0 & 94.95 & 93.6 & -1.35 \\
5 & -1 & 0 & -1 & 65.00 & 55.8 & -9.20 \\
6 & 1 & 0 & -1 & 34.40 & 39.6 & 5.20 \\
7 & -1 & 0 & 1 & 127.60 & 122.4 & -5.20 \\
8 & 1 & 0 & 1 & 158.20 & 167.4 & 9.20 \\
9 & 0 & -1 & -1 & 22.35 & 21.6 & -0.75 \\
10 & 0 & 1 & -1 & 107.95 & 97.2 & -10.75 \\
11 & 0 & -1 & -1 & 22.35 & 48.6 & 26.25 \\
12 & 0 & 1 & 1 & 115.55 & 100.8 & -14.75 \\
13 & 0 & 0 & 0 & 54.00 & 52.2 & -1.80 \\
14 & 0 & 0 & 0 & 54.00 & 54.0 & 0.00 \\
15 & 0 & 0 & 0 & 54.00 & 55.8 & 1.80 \\
\hline
\end{tabular}

agreement between the yield predicted by the model and the experimental data is very strong, with a small difference in glucose concentration.

Furthermore, the model capability was checked using the $F$-test and determination coefficient $R^{2}$. The analysis of variance (Table 4) showed that this regression model was 
TABLE 4: Analysis of variance in the regression model for optimisation of glucose production from OPEFB cellulose.

\begin{tabular}{|c|c|c|c|c|c|}
\hline Source of variations & Degree of freedom & Sum of square & Mean square & $F$ value & Determination coefficient $\left(R^{2}\right)$ \\
\hline Regression & 8 & 19264 & 240.75 & $31.14^{* *}$ & 0.9765 \\
\hline Residual & 6 & 464.04 & 77.34 & & \\
\hline Pure error & 14 & 19728.04 & 170.72 & & \\
\hline Linear & 3 & 11072.00 & 3690.67 & $47.72^{* *}$ & \\
\hline Quadratic & 2 & 2868.57 & 1434.29 & $18.55^{* *}$ & \\
\hline Cross-product & 3 & 5323.12 & 1774.37 & $22.94^{* *}$ & \\
\hline Lack of fit & 1 & 72.00 & 72.00 & 0.92 & \\
\hline Total error & 5 & 392.35 & 78.47 & & \\
\hline
\end{tabular}

$F_{0.05}(8,6)=4.15 ; F_{0.01}(8,6)=8.10 ; F_{0.05}(3,5)=5.41 ; F_{0.01}(3,5)=12.06 ; F_{0.05}(2,5)=5.79 ; F_{0.01}(2,5)=13.27 ; F_{0.05}(1,5)=6.61 ; F_{0.01}(1,5)=16.26$.

${ }^{* * *}$ Significant at $1 \%$ level.

TABLE 5: Regression analysis of a full second-order polynomial model for optimisation of glucose production from OPEFB cellulose.

\begin{tabular}{lcccc}
\hline Variables & $\begin{array}{c}\text { Standard } \\
\text { error }\end{array}$ & $t$ value & $P$-value & $\begin{array}{c}\text { Coefficient based on } \\
\text { coded value }\end{array}$ \\
\hline Intercept & 5.077401 & 10.64 & $0.0001^{* *}$ & 54.000000 \\
$x_{1}$ & 3.877929 & 2.37 & 0.0553 & 9.200000 \\
$x_{2}$ & 4.635012 & -2.32 & 0.0595 & -10.750000 \\
$x_{3}$ & 3.877929 & 12.02 & $0.0001^{* *}$ & 46.600000 \\
$x_{1} \times x_{1}$ & 6.716770 & 6.30 & $0.0007^{* *}$ & 42.300000 \\
$x_{2} \times x_{1}$ & 10.154802 & -5.82 & $0.0011^{* *}$ & -59.100000 \\
$x_{2} \times x_{2}$ & 8.028076 & 7.19 & $0.0004^{* *}$ & 57.750000 \\
$x_{3} \times x_{1}$ & 4.397158 & 3.48 & $0.0132^{*}$ & 15.300000 \\
$x_{3} \times x_{2}$ & 6.388923 & -6.70 & $0.0005^{* *}$ & -42.800000 \\
$x_{3} \times x_{3}$ & & & & 0.000000 \\
\hline
\end{tabular}

${ }^{* *}$ Significant at $1 \%$ level.

${ }^{*}$ Significant at $5 \%$ level.

highly significant $(P<0.01)$ with $F$ value of 31.14 . The suitability of model was further confirmed by a satisfactory value of the determination coefficient, which was calculated to be 0.9765 indicating that $97.65 \%$ of the variability in the response could be predicted by the model.

The regression coefficients along with the corresponding $P$ values for the model of glucose concentration produced from OPEFB cellulose are shown in Table 5. The $P$ values were used as a device to check the significance of each coefficient, and the $P$ values showed that $x_{1}^{2}$ and $x_{2}^{2}$ as well as two cross products $\left(x_{1} x_{3}\right.$ and $\left.x_{2} x_{3}\right)$ were significant.

The polynomial model for glucose concentration $(Y)$ was regressed by considering only the significant terms and shown in the following equation:

$$
\begin{aligned}
Y= & 54+46.6 x_{3}+\left(42.3 x_{1}^{2}\right)-\left(59.1 x_{2} x_{1}\right) \\
& +\left(57.75 x_{2}^{2}\right)+\left(15.3 x_{3} x_{1}\right)-\left(42.8 x_{3} x_{2}\right) .
\end{aligned}
$$

3.3.2. Canonical and Ridge Analysis. The canonical analysis of the response surface was performed with SAS to determine the shape of the fitted response and the estimated stationary point. According to the model, the predicted response at the
TABLE 6: Canonical analysis on the coded and actual value.

\begin{tabular}{lccc}
\hline Variables & Coded value & Actual value & Predicted response \\
\hline$X_{1}$ & 0.245784 & 76.245784 & \\
$X_{2}$ & 1.176647 & 1.376647 & $109.03 \mathrm{~g} / \mathrm{L}$ \\
$X_{3}$ & 2.584741 & 3.084741 & \\
\hline
\end{tabular}

TABLE 7: Eigenvalues and eigenvectors.

\begin{tabular}{lccc}
\hline Eigenvalues & \multicolumn{3}{c}{ Eigenvectors } \\
& $X_{1}$ & $X_{2}$ & $X_{3}$ \\
\hline 86.04 & 0.57 & -0.78 & 0.24 \\
21.18 & 0.81 & 0.52 & -0.23 \\
-7.17 & 0.05 & 0.33 & 0.94 \\
\hline
\end{tabular}

stationary point $\left(X_{1}=76.25, X_{2}=1.38\right.$, and $X_{3}=3.08$, shown in Table 6) was $109.93 \mathrm{~g} / \mathrm{L}$.

The three eigenvalues had different signs, indicating that the stationary point for this model was a saddle point as shown in Table 7. Therefore, the estimated surface did not have a unique optimum, and a ridge analysis was performed to determine the optimum.

The results of ridge analysis (Table 8 ) indicated that all variables tested, that is, hydrolysis reaction time, total of enzymes, and amount of substrate, were positively related to the response, and the optimal level of them was found as 76 hours and $30 \mathrm{~min}$ reaction time, $0.5 \mathrm{~mL}$ total enzymes, and $0.9 \mathrm{~g}$ of substrate (OPEFB cellulose), respectively, with a predicted glucose concentration of $169.34 \mathrm{~g} / \mathrm{L}$.

In order to confirm the predicted values, three further experiments using the optimum parameters found above were conducted and the value of 165.24-172.5 g/L (mean value $168.71 \mathrm{~g} / \mathrm{L}$ ) of glucose concentration was obtained.

The strong relationship between the yield predicted by the final quadratic model and the experimental results (Table 2 ) and the variance analysis of the second-order polynomial model and the value of lack of fit (Table 3) showed that the accuracy and overall ability of the polynomial model are very good. The analysis of response trends using the model is considered to be acceptable.

Kunamneni and Singh [18] (2005) used a central composite design (CCD) which is one of the models from response 
TABLE 8: Results of ridge analysis.

\begin{tabular}{lccccc}
\hline Radii & $\begin{array}{c}\text { Yield } \\
(\mathrm{g} / \mathrm{L})\end{array}$ & $\begin{array}{c}\text { Standard } \\
\text { error }\end{array}$ & $X_{1}$ & $X_{2}$ & $X_{3}$ \\
\hline 0.0 & 54.000000 & 5.077401 & 76.000000 & 0.200000 & 0.500000 \\
0.1 & 59.135102 & 5.088990 & 76.027497 & 0.162679 & 0.588606 \\
0.2 & 65.148586 & 5.111521 & 76.071382 & 0.099157 & 0.657274 \\
0.3 & 72.467739 & 5.161894 & 76.123974 & 0.023639 & 0.708632 \\
0.4 & 81.311717 & 5.312751 & 76.179672 & 0.055354 & 0.750024 \\
0.5 & 91.774748 & 5.661294 & 76.236446 & 0.135154 & 0.785946 \\
0.6 & 103.899910 & 6.293774 & 76.293615 & 0.215023 & 0.818662 \\
0.7 & 117.709117 & 7.258911 & 76.350935 & 0.294764 & 0.849361 \\
0.8 & 133.214604 & 8.565148 & 76.408309 & 0.374337 & 0.878709 \\
0.9 & 150.423721 & 10.197117 & 76.465695 & 0.45375 & 0.907111 \\
1.0 & 169.341156 & 12.132559 & 76.533077 & 0.533021 & 0.934823 \\
\hline
\end{tabular}

surface methodology (RSM) to optimize the effect of four variables (precooking-amylase dose, postcooking-amylase dose, glucoamylase dose, and saccharification temperature) in the optimization of glucose production from maize starch [18]. As comparison, they did 28 experiments for 4 factors and finally obtained a coefficient determination of 0.9558 , whereas in this project only 3 factors with 15 experiments were used and the coefficient determination value obtained is 0.9765 .

Although many experiments are completed at the canonical analysis, the ridge analysis is very useful to find out the maximum response which may occur in the experiment when the results of the canonical analysis shows a saddle, stationary point, and no unique optimum in the estimated surface [19]. Based on the ridge analysis, the optimal reaction time, total of enzymes, and amount of samples for glucose production were determined in this study with a good predicted hydrolysis reaction rate without further experimental work. An average glucose concentration of $168.71 \mathrm{~g} / \mathrm{L}$ was obtained in three further validation experiments using the optimum reaction parameters. As compared to those of experimental $(167.4 \mathrm{~g} / \mathrm{L})$ and predicted value $(169.34 \mathrm{~g} / \mathrm{L})$, there is a good correlation amongst those three results verifying the validity of the response model and the actuality of optimal point.

\section{Conclusions}

Enzymatic hydrolysis of OPEFB cellulose was successfully carried out at $40^{\circ} \mathrm{C}$ under various amounts of samples, total enzymes, and reaction time (48-94 hours). Box-Behnken design was shown to be useful in investigating those three critical variables. Through the canonical and ridge analyses of the second-order polynomial model, a maximum glucose concentration of $168.71 \mathrm{~g} / \mathrm{L}$ was obtained under the following conditions: 76 hours and 30 minutes hydrolysis reaction time used $0.5 \mathrm{~mL}$ enzymes and 0.9 gram samples/OPEFB cellulose. In summary, within the reaction conditions tested the concentration of glucose produced is proportional to the reaction time, total enzymes, and amount of samples.

\section{Acknowledgments}

The authors express their acknowledgements to Universiti Kebangsaan Malaysia and Malaysia Government for the financial support of this work (UKM-AP-2011-20).

\section{References}

[1] S. H. A. Rahman, J. P. Choudhury, and A. L. Ahmad, "Production of xylose from oil palm empty fruit bunch fiber using sulfuric acid," Biochemical Engineering Journal, vol. 30, no. 1, pp. 97-103, 2006.

[2] S.-P. Fan, S. Zakaria, C.-H. Chia Chin-Hua et al., "Comparative studies of products obtained from solvolysis liquefaction of oil palm empty fruit bunch fibres using different solvents," Bioresource Technology, vol. 102, no. 3, pp. 3521-3526, 2011.

[3] T. L. Chew and S. Bhatia, "Catalytic processes towards the production of biofuels in a palm oil and oil palm biomass-based biorefinery," Bioresource Technology, vol. 99, no. 17, pp. 79117922, 2008.

[4] A. Ahmadzadeh and S. Zakaria, "Kinetics of oil palm empty fruit bunch phenolysis in the presence of sulfuric acid as a catalyst," Journal of Applied Polymer Science, vol. 106, no. 5, pp. 3529-3533, 2007.

[5] L. Jiménez, L. Serrano, A. Rodríguez, and R. Sánchez, "Sodaanthraquinone pulping of palm oil empty fruit bunches and beating of the resulting pulp," Bioresource Technology, vol. 100, no. 3, pp. 1262-1267, 2009.

[6] A. Rodríguez, L. Serrano, A. Moral, A. Pérez, and L. Jiménez, "Use of high-boiling point organic solvents for pulping oil palm empty fruit bunches," Bioresource Technology, vol. 99, no. 6, pp. 1743-1749, 2008.

[7] C. E. Wyman, "Ethanol from lignocellulosic biomass: technology, economics, and opportunities," Bioresource Technology, vol. 50, no. 1, pp. 3-15, 1994.

[8] P. Zheng, L. Fang, Y. Xu, J.-J. Dong, Y. Ni, and Z.-H. Sun, "Succinic acid production from corn stover by simultaneous saccharification and fermentation using Actinobacillus succinogenes," Bioresource Technology, vol. 101, no. 20, pp. 7889-7894, 2010.

[9] E. Husson, S. Buchoux, C. Avondo et al., "Enzymatic hydrolysis of ionic liquid-pretreated celluloses: contribution of CP-MAS ${ }^{13}$ C NMR and SEM," Bioresource Technology, vol. 102, no. 15, pp. 7335-7342, 2011.

[10] S. H. A. Rahman, J. P. Choudhury, A. L. Ahmad, and A. H. Kamaruddin, "Optimization studies on acid hydrolysis of oil palm empty fruit bunch fiber for production of xylose," Bioresource Technology, vol. 98, no. 3, pp. 554-559, 2007.

[11] G. E. P. Box, W. G. Hunter, and J. S. Hunter, Statistic for Experimenters, John Wiley \& Sons, New York, NY, USA, 1978.

[12] C.-H. Dong, X.-Q. Xie, X.-L. Wang, Y. Zhan, and Y.-J. Yao, "Application of Box-Behnken design in optimisation for polysaccharides extraction from cultured mycelium of Cordyceps sinensis," Food and Bioproducts Processing, vol. 87, no. 2, pp. 139144, 2009.

[13] Chemical Analysis and Testing Standard Procedure, "National Renewable Energy Laboratories," Golden, Co., NREL, 002-004, 1996.

[14] R. El Hage, L. Chrusciel, L. Desharnais, and N. Brosse, "Effect of autohydrolysis of Miscanthus $\mathrm{x}$ giganteus on lignin structure and organosolv delignification," Bioresource Technology, vol.101, no. 23, pp. 9321-9329, 2010. 
[15] A.-I. Yeh, Y.-C. Huang, and S. H. Chen, "Effect of particle size on the rate of enzymatic hydrolysis of cellulose," Carbohydrate Polymers, vol. 79, no. 1, pp. 192-199, 2010.

[16] R. Martín-Sampedro, A. Rodríguez, A. Ferrer, L. L. GarcíaFuentevilla, and M. E. Eugenio, "Biobleaching of pulp from oil palm empty fruit bunches with laccase and xylanase," Bioresource Technology, vol. 110, pp. 371-378, 2012.

[17] H. Zhao, C. L. Jones, G. A. Baker, S. Xia, O. Olubajo, and V. N. Person, "Regenerating cellulose from ionic liquids for an accelerated enzymatic hydrolysis," Journal of Biotechnology, vol. 139, no. 1, pp. 47-54, 2009.

[18] A. Kunamneni and S. Singh, "Response surface optimization of enzymatic hydrolysis of maize starch for higher glucose production," Biochemical Engineering Journal, vol. 27, no. 2, pp. 179190, 2005.

[19] D. G. Lin, "Evolutionary technique of factorial experiment," Journal of Tropical Crops, vol. 13, pp. 51-56, 1992. 

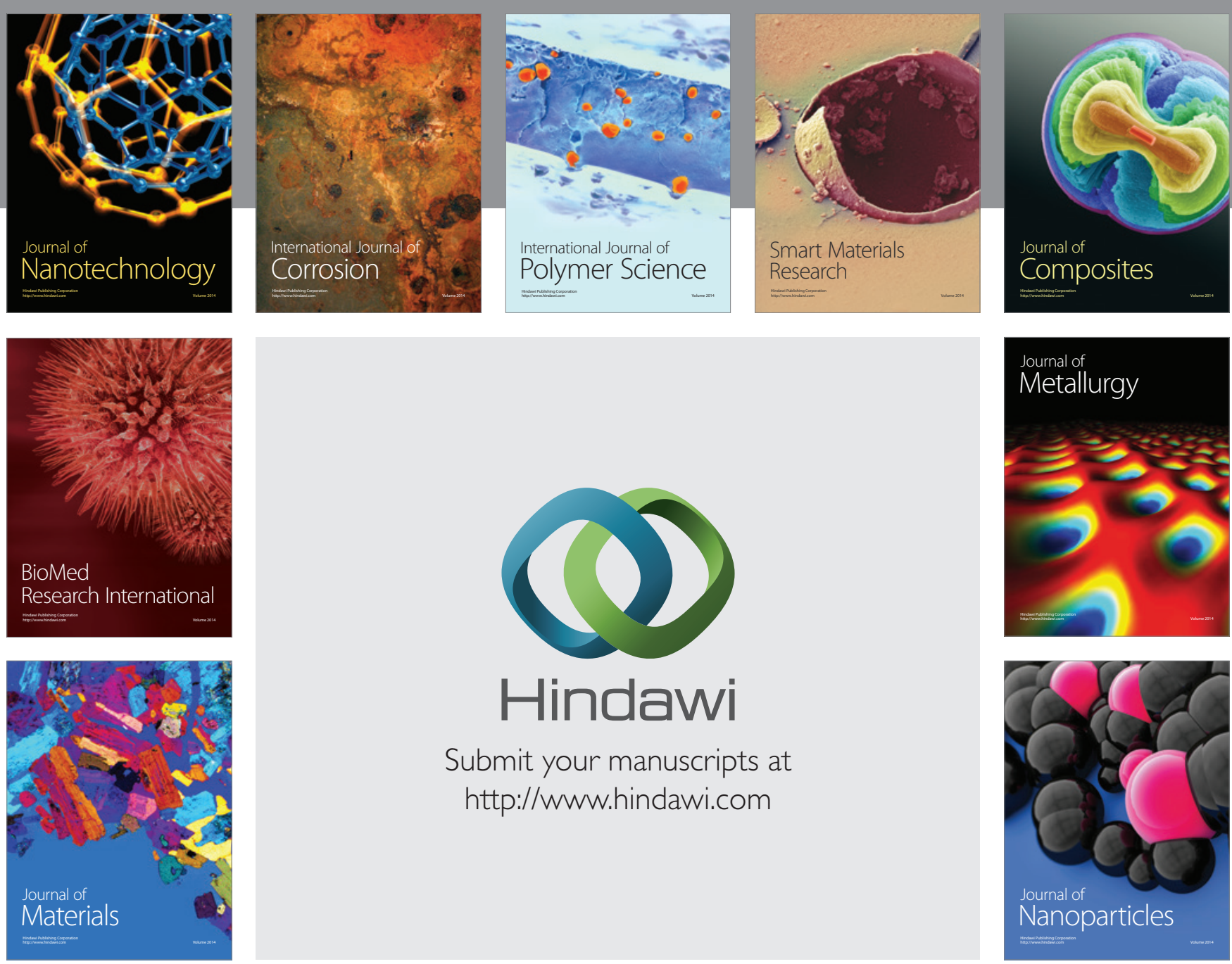

Submit your manuscripts at http://www.hindawi.com
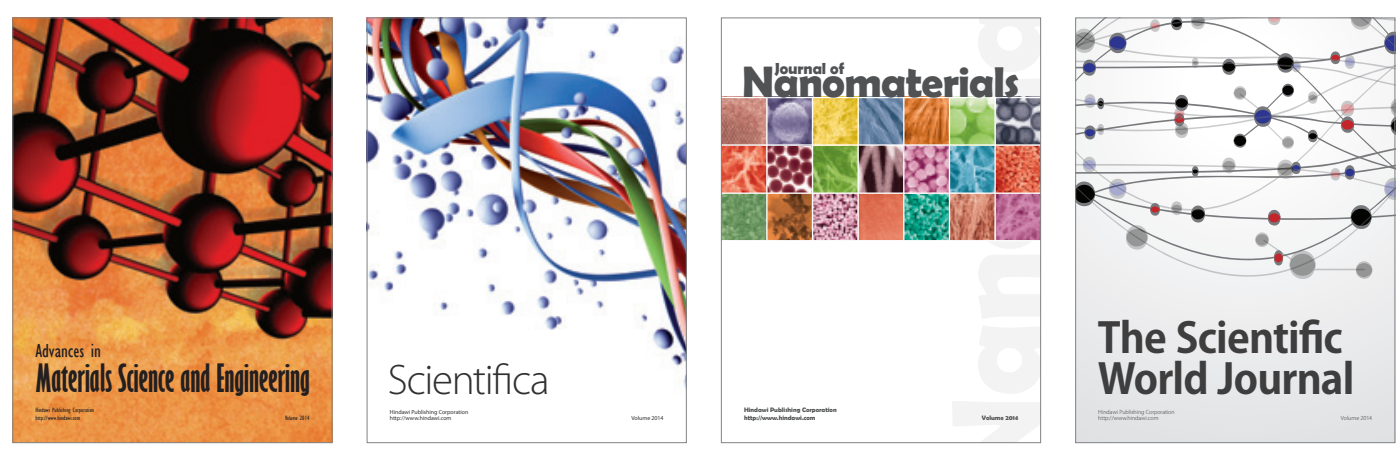

\section{The Scientific World Journal}
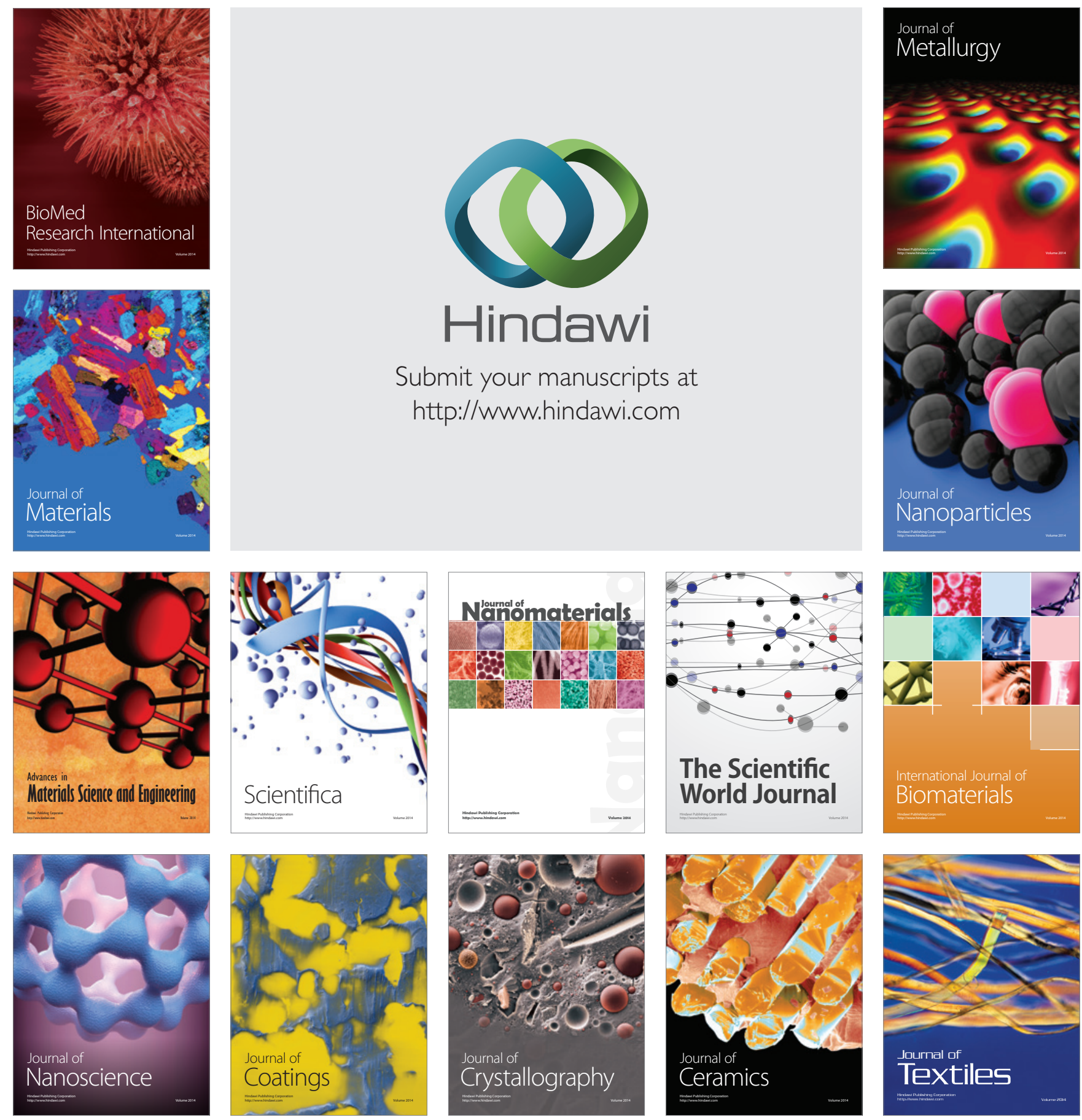